\title{
TEKNIK RELAKSASI GENGGAM JARI TERHADAP NYERI POSTSECTIO CAESAREA
}

\author{
Nita Evrianasari'), Nova Yosaria2), Anissa Ermasari3) \\ 1Prodi DIV Kebidanan Universitas Malahayati Bandar Lampung \\ Email: nita.nuninosa@gmail.com \\ 2Dinas Kesehatan Kota Metro \\ Email: novayosa87@gmail.com \\ ${ }^{3}$ Prodi DIV Kebidanan Universitas Malahayati Bandar Lampung \\ Email: anisa.as296@gmail.com
}

\begin{abstract}
Demand for caesareasectio in a number of developing countries jumps rapidly every year. Based on the results of prasurvey that researchers have done in February 2018 at RSUD A. Yani Metro City found 10 mothers with Sectio Caesarea, where 7 people (70\%) said the pain was great after Sectio Caesarea causing the mother afraid to move, 3 people (30\%) said mild pain after Sectio Caesarea but did not result in the mother afraid to move. The purpose of this study is to know the effect of hand-held relaxation techniques on post-caesarean pain in RSUD A. Yani Metro City in 2018.

Quantitative Research Type, research design pre experiment method with one group pretest posttest approach. the population in this study was 61 people. Sample as many as 20 post sectiocaesarea mother, With purposive sampling sampling technique. Data analysis with $T$-test.

The results showed the average pain before intervention was 6.30, the average pain after intervention was 4.25. There is the effect of finger hand relaxation techniques on pain of Post Sectio Caesarea in RSUD A. Yani Metro City in 2018 based on the results of $t$ test obtained $p$ value $0,000<\alpha(0,05)$. It is recommended for health workers, especially midwives, to do finger hand relaxation techniques as an alternative to reducing pain in postSC mothers.
\end{abstract}

Keywords : Hand grip relaxation technique, Pain, Post Sectio Caesarea

\section{ABSTRAK}

Permintaan sectio caesarea di sejumlah negara berkembang melonjak pesat setiap tahunnya. Angka persalinan SC di provinsi Lampung tahun 2016 sekitar 4,8\%, angka kejadian secsio caesarea di Kota Bandar Lampung pada tahun 2016 adalah 3.991 dari 169.000 persalinan (2,3\%) dari seluruh persalinan. Berdasarkan hasil prasurvey yang telah peneliti lakukan pada Bulan Agustus tahun 2017 di RSUD A. Yani Kota Metro didapatkan 10 ibu bersalin dengan Sectio Caesarea, dimana 7 orang (70\%) mengatakan nyeri sangat hebat setelah Sectio Caesarea sehingga menyebabkan ibu takut untuk bergerak, 3 orang (30\%) mengatakan nyeri ringan setelah Sectio Caesarea tetapi tidak mengakibatkan ibu takut untuk bergerak. Tujuan dari penelitian ini adalah diketahui adanya Pengaruh Teknik Relaksasi Genggam Jari Terhadap Nyeri PostSectio Caesarea di RSUD A. Yani Kota Metro tahun 2018.

Jenis Penelitian Kuantitatif, rancangan penelitian metode pra eksperimen dengan pendekatan one group pretest posttest. populasi dalam penelitian ini adalah 61 orang. Sampel sebanyak 20 orang ibu post Sectio Caesarea diambil dengan teknik purposive sampling. Analisa data dengan uji T-test.

Hasil penelitian menunjukan rata-rata nyeri sebelum intervensi sebesar 6.30, rata-rata nyeri setelah intervensi sebesar 4.25. Ada pengaruh teknik relaksasi genggam jari terhadap nyeri Post Sectio Caesarea di RSUD A. Yani Kota Metro berdasarkan hasil uji t didapat $p$ value $0,000<a(0,05)$. Disarankan bagi tenaga kesehatan khususnya bidan agar melakukan teknik relaksasi genggam jari sebagai salah satu alternative penurunan nyeri pada ibu post SC.

Kata Kunci : Teknik relaksasi genggam jari, Nyeri, Pasca Operasi Sectio Caesarea 


\section{PENDAHULUAN}

Persalinan normal menurut WHO (2010) adalah persalinan yang dimulai secara spontan, berisiko rendah pada awal persalinan, dan tetap demikian selama proses persalinan, bayi lahir secara spontan dalam presentasi belakang kepala pada usia kehamilan 37-42 minggu lengkap dan setelah persalinan ibu maupun bayi berada dalam kondisi sehat. (Oktarina, 2015)

Banyak jenis persalinan seperti persalinan normal dan melalui sectio caesarea, dimana setiap persalinan pasti mengalami nyeri baik pervaginam maupun persalinan secara operasi seperti sectio caesarea (SC). Persalinan SC dapat menimbulkan sensasi nyeri yang bukan lagi nyeri fisiologis dari persalinannya tetapi juga nyeri dari luka sayatan pada area yang dibedah (Prawirohardjo, 2009).

Menurut World Health Organization (WHO) standar rata-rata sectio caesarea di negara berkembang adalah sekitar $5-15 \%$ per 1000 kelahiran, Tindakan SC di rumah sakit pemerintah rata-rata sekitar $11 \%$ sementara di rumah sakit swasta bisa lebih dari 30\%. Di Amerika Serikat dilaporkan setiap tahunnya terjadi peningkatan Sectio Caesarea dimana terdapat $27 \%$ dari seluruh proses melahirkan dilakukan SC dan dari angka tersebut $19,1 \%$ merupakan sectio caesarea primer, dari laporan dinyatakan bahwa sectio caesarea primer terbanyak tanpa komplikasi. Angka ini meningkat masing-masing $49,7 \%$ dan $51 \%$ (Sulistyawati, Nugraheny, 2010). Pada tahun 2012 angka kejadian sectio caesarea mencapai $26,1 \%$, angka tertinggi yang pernah tercatat di Amerika Serikat.

Pada tahun 70an persalinan dengan sectio caesarea atas dasar permintaan sebesar $5 \%$, kini lebih dari $50 \%$ ibu hamil menginginkan operasi sectio caesarea. Menurut WHO, peningkatan persalinan dengan operasi sesar di seluruh negara terjadi semenjak tahun 2007- 2008 yaitu 110.000 per kelahiran diseluruh Asia, Novita, D., Donel, S., \& Nurlisis, N. (2018)). Hasil Riskesdas tahun 2013 menunjukkan kelahiran dengan metode operasi sesar sebesar 9,8 persen dari total 49.603 kelahiran sepanjang tahun 2010 sampai dengan 2013. Kejadian Sectio caesarea di Provinsi Lampung tahun 2016 sekitar 4,8\%, dan angka kejadian di Kota Bandar Lampung adalah 3.991 dari 169.000 persalinan $(2,3 \%)$ dari seluruh persalinan (Dinkes Provinsi Lampung, 2016).

Rasa nyeri pada proses pembedahan sectio caesarea merupakan respon nyeri yang dirasakan oleh pasien yang efek samping setelah menjalani suatu operasi. Nyeri yang disebabkan oleh operasi biasanya membuat pasien merasa sangat kesakitan. Ketidaknyamanan atau nyeri merupakan keadaan yang harus diatasi dengan manajemen nyeri, karena kenyamanan merupakan kebutuhan dasar manusia. (Petasik et all, 2013)

Manajemen nyeri dapat dilakukan dengan beberapa tindakan atau prosedur baik secara farmakologis maupun non farmakologis. Prosedur secara farmakologis dilakukan dengan pemberian analgesik, yaitu untuk mengurangi atau menghilangkan rasa nyeri, sedangkan secara non farmakologis dapat dilakukan dengan cara relaksasi, teknik pernapasan, pergerakan/perubahan posisi, massage, akupressur, terapi panas/dingin, hypnobirthing, musik, dan TENS (Transcutaneous ElectricalNerve Stimulation) (Potter,Perry 2005).

Salah satu manajemen nyeri secara nonfarmakologis yang dapat dilakukan adalah teknik relaksasi genggam jari. Teknik relaksasi genggam jari merupakan cara yang mudah untuk mengelola emosi dan mengembangkan kecerdasan emosional. Di sepanjang jari-jari tangan terdapat saluran atau meridian energi yang terhubung dengan berbagai organ dan emosi. Titik-titik refleksi pada tangan memberikan rangsangan secara refleks (spontan) pada saat genggaman. Rangsangan tersebut akan mengalirkan semacam gelombang kejut atau listrik menuju otak. Gelombang tersebut diterima otak dan diproses dengan cepat diteruskan menuju saraf pada organ tubuh yang mengalami gangguan, sehingga sumbatan di jalur energi menjadi lancer. Teknik relaksasi genggam jari membantu tubuh, pikiran dan jiwa untuk mencapai relaksasi. Dalam keadaan relaksasi secara alamiah akan memicu pengeluaran hormon endorfin, hormon ini merupakan analgesik alami dari tubuh sehingga nyeri akan berkurang.

Asuhan kebidanan pasca persalinan yang meliputi biologis, psikologis, sosial, dan spiritual diperlukan untuk meningkatkan status kesehatan ibu dan anak terutama pada masa nifas. Masa nifas merupakan masa yang relatif tidak komplek dibandingkan dengan kehamilan, masa nifas ditandai oleh banyaknya perubahan fisiologi. Pada masa nifas ini berbagai komplikasi persalinan post sectio caesarea dapat dialami oleh ibu, dan apabila tidak segera ditangani dengan baik akan memberi kontribusi yang cukup besar terhadap tingginya angka kematian ibu di Indonesia.

Berdasarkan hasil prasurvey yang telah peneliti lakukan pada bulan Agustus tahun $2018 \mathrm{di}$ RSUD A. Yani Kota Metro didapatkan 10 ibu bersalin dengan sectio caesarea, dimana 7 orang $(70 \%)$ mengatakan nyeri sangat hebat setelah sectio caesarea sehingga menyebabkan ibu takut 
untuk bergerak, 3 orang (30\%) mengatakan nyeri ringan setelah sectio caesarea tetapi tidak mengakibatkan ibu takut untuk bergerak, dibandingkan dengan RS Muhammadiyah Kota Metro yang hanya terdapat 5 ibu bersalin dengan sectio caesarea, dimana 3 orang $(60 \%)$ mengatakan nyeri hebat setelah sectio caesarea sehingga menyebabkan ibu takut untuk bergerak, 2 orang $(40 \%)$ mengatakan nyeri ringan setelah sectio caesarea tetapi tidak mengakibatkan ibu takut untuk bergerak.

\section{METODE PENELITIAN}

Jenis penelitian dalam penelitian ini adalah kuantitatif dengan pendekatan pra eksperimen dengan rancangan one group pretest-posttest design. Prosedur penelitian ini dengan memberikan intervensi kepada responden yang akan dilakukan tindakan perlakuan dan membandingkan hasil dari pengukuran sebelum dan sesudah dilakukan intervensi. Penelitian dilakukan pada bulan Agustus 2017 s.d. Februari 2018

\section{HASIL PENELITIAN DAN PEMBAHASAN}

Tabel 1 Karakteristik Responden

\begin{tabular}{|c|c|c|c|c|c|c|}
\hline No & Usia & Frekuensi & Presentase $(\%)$ & $\begin{array}{c}\text { Nyeri } \\
\text { Sebelum }\end{array}$ & $\begin{array}{c}\text { Nyeri } \\
\text { Sesudah }\end{array}$ & Penurunan \\
\hline 1 & $<20$ tahun & 0 & 0 & & & \\
\hline 2 & 20-30 tahun & 14 & 70.0 & 6.5 & 4.4 & 2.1 \\
\hline \multirow[t]{2}{*}{3} & $>30$ tahun & 6 & 30.0 & 6.0 & 4.0 & 2.0 \\
\hline & Total & 20 & 100.0 & & & \\
\hline No & Paritas & Frekuensi & Presentase (\%) & & & \\
\hline 1 & $\mathrm{G}_{1} \mathrm{P}_{0} \mathrm{~A}_{0}$ & 4 & 20.0 & 7.5 & 5.4 & 2.1 \\
\hline 2 & $\mathrm{G}_{2} \mathrm{P}_{1} \mathrm{~A}_{0}$ & 12 & 60.0 & 6.0 & 4.0 & 2.0 \\
\hline \multirow[t]{2}{*}{3} & $\mathrm{G}_{3} \mathrm{P}_{2} \mathrm{~A}_{0}$ & 4 & 20.0 & 6.0 & 4.0 & 2.0 \\
\hline & Total & 20 & 100.0 & & & \\
\hline No & Pendidikan & Frekuensi & Presentase (\%) & & & \\
\hline 1 & SMA & 13 & 65.0 & 6.4 & 4.4 & 2.0 \\
\hline 2 & D3 & 4 & 20.0 & 6.0 & 4.0 & 2.0 \\
\hline \multirow[t]{2}{*}{3} & S1 & 3 & 15.0 & 6.0 & 4.0 & 2.0 \\
\hline & Total & 20 & 100.0 & & & \\
\hline
\end{tabular}

Karakteristik usia responden yang paling tinggi mengalami penurunan nyeri adalah ibu dengan usia 20-30 tahun dimana rata-rata penurunan nyeri sebesar 2.1 dengan nyeri sebelum intervensi sebesar 6.5 dan nyeri sesudah intervensi sebesar 4.4 , karakteristik paritas yang paling tinggi mengalami penurunan nyeri adalah ibu dengan paritas pertama dimana rata-rata penurunan nyeri sebesar 2.1 dengan nyeri sebelum intervensi
Populasi dalam penelitian ini adalah ibu bersalin dengan sectio caesarea di RSUD A.Yani Kota Metro pada periode bulan Oktober 2017. Sampel diambil dengan tekhnik purposif sampling dengan kriteria inklusi 1) 7-8 Jam post pemberian analgetik 2)Mendapat analgetika sammefenamat dan Kriteria Eksklusi 1) Pasien dengan kaku otot. Didapatkan sampel sebanyak 20 responden.

Tekhnik genggam jari dilakukan dengan cara Genggam ibu jari selama kurang lebih 3 menit dengan bernapas secara teratur, untuk kemudian seterusnya satu persatu beralih ke jari selanjutnya dengan rentang waktu yang sama, setelah kurang lebih 15 menit, alihkan tindakan untuk tangan yang lain danlakukanjugaselama 15 menit.

Pengukuran tingkat nyeri dengan menggunakan skala nyeri numerik (0-10).

Tekhnik analisa data yang digunakan adalah uji statistik "Uji $T$ - testdependent". H0 ditolak jika $p$ value $\leq 0,05$ berarti ada pengaruh yang signifikan antara kedua variabel yang diteliti dan $\mathrm{HO}$ gagal ditolak jika $p$-value $\geq 0,05$ berarti tidak ada pengaruh yang signifikan (Hastono, 2007). 
Tabel 2 Rata-Rata Nyeri Sebelum Dilakukan Teknik Relaksasi Genggam Jari

\begin{tabular}{ccccccc}
\hline Variabel & $\mathrm{N}$ & Mean & Median & SD & Min & Max \\
\hline Hasil Pengukuran nyeri sebelum intervensi & 20 & 6,30 & 6,00 & 0,657 & 6 & 8 \\
\hline
\end{tabular}

Tabel 3 Rata-Rata Nyeri Sesudah Dilakukan Teknik Relaksasi Genggam Jari

\begin{tabular}{ccccccc}
\hline Variabel & $\mathrm{N}$ & Mean & Median & SD & Min & Max \\
\hline $\begin{array}{c}\text { Hasil Pengukuran nyeri } \\
\text { sesudah intervensi }\end{array}$ & 20 & 4,25 & 4,00 & 0,639 & 4 & 6 \\
\hline
\end{tabular}

Nilai mean ataunilai rata-rata nyeri sesudah diberikan intervensi sebesar 4,25, dengan nilai median 4,00, standar deviasi sebesar 0,639, hasil rata-rata terendah atau hasil minimal yaitu sebesar 4 dan hasil jumlah tertinggi atau hasil maximal sebesar 6 .

\section{Analisa Bivariat}

Tabel 4 Pengaruh Teknik Relaksasi Genggam Jari Terhadap Nyeri PostSectio Caesarea

\begin{tabular}{lccccc}
\hline \multicolumn{1}{c}{ Hasil Pengukuran nyeri } & N & Mean & SD & SE & $P$ value \\
\hline Sebelum & 20 & 6,30 & 0,657 & 0,147 & \multirow{2}{*}{0.000} \\
Sesudah & 20 & 4,25 & 0,639 & 0,143 & \\
\hline
\end{tabular}

Hasil uji t didapat $p$ value $0,000 \leq a(0,05)$ artinya $\mathrm{HO}$ ditolak dan $\mathrm{Ha}$ diterima, yang berarti ada pengaruh teknik relaksasi genggam jari terhadap nyeri postsectio caesarea di RSUD A. Yani Kota Metro tahun 2018.

\section{PEMBAHASAN}

Hasil penelitian diketahui bahwa dari 20 responden penelitian, diperoleh hasil nilai mean atau nilai rata-rata nyeri sebelum diberikan intervensi sebesar 6,30 dengan nilai median 6,00, standar deviasi sebesar 0,657 , hasil rata-rata terendah atau hasil minimal yaitu sebesar 6 dan hasil jumlah tertinggi atau hasil maximal sebesar 8.Sedangkan nilai rata-rata nyeri sesudah diberikan intervensi sebesar 4,25, dengan nilai median 4,00, standar deviasi sebesar 0,639 , hasil rata-rata terendah atau hasil minimal yaitu sebesar 4 dan hasil jumlah tertinggi atau hasil maksimal sebesar 6 .

Berdasarkan teori rasa nyeri merupakan sebagai pengalaman sensori dan emosional yang tidak menyenangkan yang berhubungan dengan kerusakan jaringan aktual atau potensial. Proses kerusakan jaringan diteruskan ke sistem saraf pusat dan menimbulkan sensasi nyeri. Penilaian nyeri tidak dapat lepas dari subjektivitas klien. Untuk membantu manajemen nyeri agar dapat lebih objektif, maka dibuat skala kuantitas (Mander, 2003).

Nyeri merupakan salah satu keluhan tersering pada pasien setelah mengalami suatu tindakan pembedahan. Pembedahan merupakan suatu peristiwa yang bersifat bifasik terhadap tubuh manusia yang berimplikasikan pada pengelolaan nyeri. Lama waktu pemulihan pasien post operasi normalnya terjadi hanya dalam satu sampai 2 jam, sehingga pasien akan merasakan nyeri yang hebat pada 2 jam pertama sesudah operasi karena pengaruh obat anastesi sudah hilang, dan pasien sudah keluar dari kamar sadar (Potter et all, 2005).

Manajemen nyeri mempunyai beberapa tindakan atau prosedur baik secara farmakologis maupun non farmakologis. Prosedur secara farmakologis dilakukan dengan pemberian analgesik, yaitu untuk mengurangi atau menghilangkan rasa nyeri. Sedangkan secara non farmakologis dapat dilakukan dengan cara relaksasi dengan menggunakan aromaterapi, teknik pernapasan, pergerakan/perubahan posisi, massage, akupressur, terapi panas/dingin, hypnobirthing, musik, dan TENS (Transcutaneous ElectricalNerve Stimulation) (Potter, et all 2005).

Tekhnik genggam jari merupakan salah satu praktik yang dapat membatu meredakan nyeri. Tekhnik genggam jari dapat menghilangkan secara cepat Khawatir, rasa takut, marah dan kesedihan. Masing-masing genggaman jari memiliki manfaat tersendiri, diantaranya, genggaman pada ibu jari bermanfaat untuk mengurangi kekhawatiran, manfaat tambahan untuk depresi, kebencian, obsesi, kecemasan, perlindungan diri, hingga merevitalisasi kelelahan fisik. Genggaman pada jari telunjuk memiliki tujuan utama untuk mengurang 
rasa takut, selian itupun dapat membantu pada kondisi depresi, frustasi, maslah pencernaan, eliminasi, dan ketidaknyamanan. Genggaman pada jari tengah secara umum berfungsi untuk mengatasi kemarahan, dan memiliki manfaat tambahan untuk mengurangi rasa mudah tersinggung, tidak stabil, kelelahan umum dan ketidaknyamanan pada dahi. Genggaman pada jari manis berfungsi secra umum untuk mengatasi rasa kesedihan, fungsi tambahan untuk mengatasi perasaan negatif, kenyaman pernafasan dan ketidaknyaman pada telinga. Semantara itu, genggaman pada jari kelingking mempinyai manfaat untuk mengurangi rasa tidak nyaman, releksasi dan gangguan pada pencernaan. (Henderson, 2007)

Hasil Penelitian ini sejalan dengan penelitian yang telah dilakukan oleh Pinandita (2012).Dengan judul "Pengaruh Teknik Relaksasi Genggam Jari Terhadap Penurunan Intensitas Nyeri Pada Pasien Post Operasi Laparatomi RS.PKU Muhammadiyah Gombong" didapatkan hasil pada kelompok eksperimen, intensitas nyeri pre tes memiliki mean 6.64 dan intensitas nyeri post test memiliki mean 4.88.Pada kelompok kontrol, intensitas nyeri pre tes memiliki mean 6.58 dan intensitas nyeri post test memiliki mean 6.47. Perbedaan rata-rata intensitas nyeri pre testposttest pada kelompok eksperimen adalah 1.764 dan perbedaan rata-rata intensitas nyeri pre testposttest pada kelompok kontrol adalah 0.117 . Berdasarkan harga signifikansi $(p)$, dimana nilai $p=0.000$, dimana nilai tersebut $(p<0.05)$, artinya terdapat pengaruh teknik relaksasi genggam jari terhadap penurunan intensitas nyeri pada pasien post operasi laparatomi di RS PKU Muhammadiyah Gombong.

Hasil analisa bivariat menggunakan uji t test sample dependent didapatkan nilai $p$-value sebesar $0.000<a(0,05)$ yang berarti ada pengaruh teknik relaksasi genggam jari terhadap nyeri Post Sectio Caesarea di RSUD A. Yani Kota Metro tahun 2018.

Hasil ini memiliki kesesuaian dengan teori relaksasi genggam jari yang menyebutkan bahwa tehnik relaksasi genggam jari menghasilkan impuls yang dikirim melalui serabut saraf aferen nonnosiseptor. Serabut saraf aferen non-nosiseptor mengakibatkan "gerbang" tertutup sehingga stimulus pada kortek serebri dihambat atau dikurangi akibat counter stimulasi relaksasi dan menggenggam jari. Sehingga intensitas nyeri akan berubah atau mengalami modulasi akibat stimulasi relaksasi genggam jari yang lebih dahulu dan lebih banyak mencapai otak. (Astuti, 2017)

Relaksasi genggam jari dapat mengendalikan dan mengembalikan emosi yang akan membuat tubuh menjadi rileks. Adanya stimulasi nyeri pada luka bedah menyebabkan keluarnya mediator nyeri yang akan menstimulasi transmisi impuls disepanjang serabut afaren nosiseptor ke substansi gelatinosa (pintu gerbang) di medula spinalis untuk selanjutnya melewati thalamus kemudian disampaikan ke kortek serebri dan di interpretasikan sebagai nyeri. Perlakuan relaksasi genggam jari akan menghasilkan impuls yang dikirim melalui serabut saraf aferen nosiseptor - non nosiseptor.Serabut saraf non nosiseptor mengakibatkan "pintu gerbang" tertutup sehingga stimulus nyeri terhambat dan berkurang.Teori two gate control menyatakan bahwa terdapat satu pintu "pintu gerbang" di thalamus mengakibatkan stimulasi yang menuju konteks serebri terhambat sehingga intensitas nyeri berkurang untuk kedua kalinya (Pinandita, 2012).

Berdasarkan teori gate-control menjelaskan bahwa teori gate control bahwa stimulasi kulit akan mengaktifkan tranmisi serabut saraf sensori A-Beta yang lebih besar dan lebih cepat. Apabila terdapat impuls yang ditransmisikan oleh selaput berdiameter besar karena adanya stimulasi kulit, sentuhan, getaran, hangat dan dingin serta sentuhan halus, maka impuls ini akan menghambat impuls dari serabut berdiameter kecil di area substansia galatinosa, sehingga tubuh tidak akan merasakan nyeri (Oktarina, 2018)

Hasil Penelitian ini sejalan dengan penelitian yang telah dilakukan oleh Ma'rifah, (2015) tentang efektifitas relaksasi genggam jari terhadap penurunan skala nyeri pada pasien Post Operasi Sectio Caesarea di RSUD Prof. Dr. Margono Soekardjo Purwokerto dengan hasil uji $p$ value sebesar 0,001 $(p<a)$, maka dapat disimpulkan bahwa ada perbedaan yang signifikan skala nyeri sebelum dan sesudah diberikan tehnik relaksasi genggam jari pada kelompok eksperimen dengan selisih rata-rata penurunan nyeri adalah 1,54, sehingga dapat disimpulkan teknik relaksasi genggam jari mempunyai nilai efektifitas lebih baik dalam menurunkan nyeri post operasi.

Menurut pendapat peneliti, pada pembedahan sectio caesarea rasa nyeri biasanya dirasakan pasca melahirkan, karena pada waktu proses pembedahan sectio caesarea dokter telah melakukan pembiusan. Pengaruh obat bius biasanya akan menghilang sekitar 2 jam setelah proses persalinan selesai. Setelah efek bius habis, rasa nyeri pada bagian perut mulai terasa karena luka yang terdapat di bagian perut. Nyeri pasca bedah akan menimbulkan reaksi fisik dan psikologi pada ibu postpartum seperti mobilisasi terganggu, malas beraktifitas, sulit tidur, tidak nafsu makan, tidak mau merawat bayi sehingga perlu adanya cara untuk mengontrol nyeri agar dapat beradaptasi dengan nyeri post operasi sectio caesarea dan mempercepat masa nifas didapatkan tingkat nyeri pada ibu berbeda-beda hal tersebut dapat berkaitan dengan karakteristik usia dan paritas ibu, ibu dimana karakteristik usia responden yang paling 
tinggi mengalami penurunan nyeri adalah ibu dengan usia 20-30 tahun dimana rata-rata penurunan nyeri sebesar 2.1 dengan nyeri sebelum intervensi sebesar 6.5 dan nyeri sesudah intervensi sebesar 4.4, karakteristik paritas yang paling tinggi mengalami penurunan nyeri adalah ibu dengan paritas pertama dimana-rata-rata penurunan nyeri sebesar 2.1 dengan nyeri sebelum intervensi sebesar 7.5 dan nyeri sesudah intervensi sebesar 5.4..

\section{SIMPULAN}

Rata-rata nyeri sebelum dilakukan teknik relaksasi genggam jari terhadap ibu bersalin postsectio caesarea di RSUD A. Yani Kota Metro tahun 2018 yaitu sebesar, 6.30. Rata-rata nyeri sesudah dilakukan teknik relaksasi genggam jari terhadap ibu bersalin postsectio caesarea di RSUD A. Yani Kota Metro tahun 2018 yaitu sebesar 4.25.Ada pengaruh teknik relaksasi genggam jari terhadap nyeri postsectio caesareadi RSUD A. Yani Kota Metro tahun 2018, analisa data menggunakan uji t didapat $p$ value $0,000 \leq a 0.05$.

\section{SARAN}

Sebagai bahan informasi bagi tempat penelitian agar melakukan teknik relaksasi dan melakukan sosialisasi pada kelas ibu hamil, khususnya ibu hamil dengan primigravida, karena ibu dengan primigravida akan mengalami nyeri lebih tinggi dibandingkan dengan ibu hamil dengan multigravida sehingga dapat digunakan untuk menurunkan nyeri post sectio caesarea pada ibu bersalin.

\section{DAFTAR PUSTAKA}

Astutik, P., \& Kurlinawati, E. (2017). Pengaruh Relaksasi Genggam Jari Terhadap Penurunan Nyeri Pada Pasien Post Sectio Caesarea. STRADA Jurnal IImiah Kesehatan, 6(2), 30-37.

Dinas Kesehatan Propinsi Lapung. Profil Kesehatan Provinsi Lampung Tahun 2016 [Internet]. http://www.depkes.go.id/resources/downlo ad/profil/PROFIL_KES_PROVINSI_2016/0 8_Lampung_2016.pdf

Hastono, S. P. (2007). Analisis data kesehatan: Basic data analysis for health research training. FKM UI.

Henderson, Jan. 2007. Acupressure Self-Help: Daily Practices For Balancing Energy Flow Three practices For Brushing Energy Through The Body. Dalam http://workingwell.org/Website/ pdf.file/AcupressureDailypractices.pdf. (diakses pada tanggal 10 Maret 2018)
Kementerian Kesehatan. Laporan Nasional Riset Kesehatan Dasar 2013 [Internet]. Jakarta: Badan Litbang Kesehatan; 2013. Available from:

http://www.litbang.depkes.go.id/sites/do wnload/rkd2013/LaporanRiskesdas2013. PDF

Ma'rifat, A. R., Handayani, R. N., \& Dewi, P. (2015). Efektifitas Relaksasi Genggam Jari Terhadap Penurunan Skala Nyeri pada Pasien Post Operasi Sectio Caesarea di Rsud Prof. Dr. Margono Soekardjo Purwokerto. Jurnal Keperawatan 'Aisiyah, 2(1), 63-67.

Mander, R. (2003). Nyeri persalinan. EGC

Oktarina, M. (2015). Buku Ajar Asuhan Kebidanan Persalinan dan Bayi Baru Lahir. Deepublish.

Oktarina, N. D., Suwanti, S., \& Rosyidi, M. I. (2018). STIMULASI KUTANEUS LEBIH EFEKTIF MENURUNKAN NYERI DISMENORE PADA REMAJA DIBANDINGKAN DENGAN KUNYIT ASAM. Jurnal Keperawatan dan Kesehatan Masyarakat Cendekia Utama, 7(2), 143-153.

Patasik, C. K., Tangka, J., \& Rottie, J. (2013). Efektifitas Teknik Relaksasi Nafas Dalam Dan Guided Imagery Terhadap Penurunan Nyeri Pada Pasien Post Operasi Sectio Caesare Di Irina D Blu Rsup Prof. Dr. RD Kandou Manado. JURNAL KEPERAWATAN, 1(1).

Perry, A. G., \& Potter, P. A. (2005). Buku ajar fundamental keperawatan; Konsep, proses dan praktik, Vol. 2 Alih Bahasa. Editor Monica Ester Dkk, Jakarta: EGC.

Pinandita, I., Purwanti, E., \& Utoyo, B. (2012). Pengaruh teknik relaksasi genggam jari terhadap penurunan intensitas nyeri pada pasien post operasi laparatomi. Jurnal Ilmiah Kesehatan Keperawatan, 8(1).

Prawirohardjo, S. (2009). IImu kebidanan. Jakarta: Yayasan.

Sofiyah, L., Ma'rifah, A. R., \& Susanti, I. H. (2014). PENGARUH TEKNIK RELAKSASI GENGGAM JARI TERHADAP PERUBAHANSKALA NYERI PADA PASIEN POST OPERASI SECTIO CAESAREADI RSUD PROF. DR. MARGONO SOEKARDJO PURWOKERTO. II PROSIDING SEMINAR NASIONAL INTERNASIONAL (Vol. 2, No. 2).

Sulistyawati, A., \& Nugraheny, E. (2010). Asuhan kebidanan pada ibu bersalin. Jakarta: Salemba Medika, 4. 